EPJ Web of Conferences 32, 04012 (2012)

DOI: $10.1051 /$ epjconf/20123204012

(C) Owned by the authors, published by EDP Sciences, 2012

\title{
Recent Progress of 2MW 140GHz ECRH System on HL-2A
}

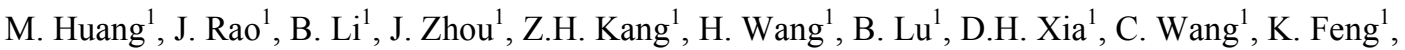 \\ M.W. Wang ${ }^{1}$, G.Y. Chen ${ }^{1}$, Y.N. Pu ${ }^{1}$, Z.H. Lu ${ }^{1}$, J.Q. Wang ${ }^{1}$, X.R. Duan ${ }^{1}$, Y. Liu ${ }^{1}$ \\ ${ }^{1}$ Southwestern Institute of Physics, P.O. Box 432, Chengdu, China
}

\begin{abstract}
In order to provide more capability of physics study for high-performance plasma, such as current profile control, neoclassical tearing modes suppression, transport study and so on, a new $2 \mathrm{MW} / 140 \mathrm{GHz} / 3$ s second-harmonic ECRH system with X-mode injection is on schedule on HL-2A. The total power of this system is $2 \mathrm{MW}$ and the pulse duration is $3 \mathrm{sec}$, which is generated by two gyrotrons manufactured by GYCOM. Two evacuated $\Phi 63.5 \mathrm{~mm}$ transmission lines were used to propagate these two $1 \mathrm{MW} / 3 \mathrm{~s}$ wave beams. A fast steerable launcher has been designed and installed on the HL-2A tokamak to inject four beams with narrow beam width and enable continuous beam scanning in toroidal and poloidal directions independently.
\end{abstract}

\section{Introduction}

Electron cyclotron heating (ECRH) and electron cyclotron current drive (ECCD) has been proven to be one of the most effective and promising methods for plasma heating and current profile control for present and future nuclear fusion research ${ }^{[1-3]}$, also on HL-2 $\mathrm{A}^{[4-5]}$. HL-2A is a medium size tokamak with major radius of $1.65 \mathrm{~m}$ and minor radius of $0.4 \mathrm{~m}$. The toroidal magnetic field could be operated at $\sim 2.4 \mathrm{~T}$ or $\sim 1.2 \mathrm{~T}$. As the main heating method, until $2010,3 \mathrm{MW} / 68 \mathrm{GHz}$ ECRH system

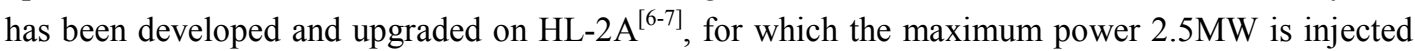
into plasma. The installed 3MW/68GHz HL-2A ECH/ECCD system has six $0.5 \mathrm{MW}$ gyrotrons, six non-evacuated $10 \mathrm{~m}$-long transmission lines ${ }^{[8]}$, and two types of launchers. Launcher A1 was fabricated for two wave beams and the injection angles could only be changed in the toroidal direction with $0^{\circ}-20^{\circ}$ by manual. ${ }^{[9]}$ Launcher A2 has the function to inject four wave beams into plasma with the fixed mirrors. ${ }^{[10]}$

In order to provide more capability of physics study for high-performance plasma, such as active current profile control, neoclassical tearing modes suppression, transport study and so on, a new 2MW/140GHz/3s second-harmonic ECRH system with X-mode injection is on schedule on HL-2A. For the on-going $140 \mathrm{GHz}$ system, the output power of one gyrotron is $1 \mathrm{MW} / 3 \mathrm{~s}$. A kind of evacuated $\Phi 63.5 \mathrm{~mm}$ transmission line has been considered in this case. A fast steerable ECH/ECCD launcher should have the capability to change the ECW injection angle in poloidal and toroidal angles, and the scan range should satisfy the requirement of ECH/ECCD experiments on HL-2A. For the limited tokamak ports, this launcher will replace the old launcher A1 and inject these two $140 \mathrm{GHz}$ wave beams and another two $500 \mathrm{~kW} / 68 \mathrm{GHz} / 1 \mathrm{~s}$ wave beams into plasma from the low-field side through one $\Phi 350 \mathrm{~mm}$ equatorial tokamak port. The comparison of $68 \mathrm{GHz}$ and $140 \mathrm{GHz}$ ECRH systems are shown in Table 1 and the layout of the overall ECRH system on HL-2A is shown in Fig. 1. 
Table 1 comparison of $68 \mathrm{GHz}$ and $140 \mathrm{GHz}$ ECRH system

\begin{tabular}{|c|c|c|c|c|}
\hline Power & Frequen $\phi y$ & Pulse 0 & Transmission line & Launcher (by a $\Phi 350 \mathrm{~mm}$ tokamak port) \\
\hline $\begin{array}{l}3 \mathrm{MW} \\
\left(6^{*} 0.5\right)\end{array}$ & $68 \mathrm{GHz}$ & $\begin{array}{c}4 * 1 \mathrm{~s} \\
2 * 1.5 \mathrm{~s}\end{array}$ & $\begin{array}{l}\text { Ф80mm, non- } \\
\text { evacuated }\end{array}$ & $\begin{array}{c}\mathrm{A} 1: 1 * 2 \text { beams, toroidal angle } 0^{0}-25^{0} \\
\mathrm{~A} 2: 2 * 2, \text { fixed mirrors }\end{array}$ \\
\hline $\begin{array}{l}2 \mathrm{MW} \\
(2 * 1)\end{array}$ & $140 \mathrm{GHz}$ & $3 \mathrm{~s}$ & $\begin{array}{l}\Phi 63.5 \mathrm{~mm} \\
\text { evacuated }\end{array}$ & $\begin{array}{l}\text { A3: } 2 * 2 \text { beams (two } 68 \mathrm{GHz} \text { and two } \\
140 \mathrm{GHz} \text { ), two-dimension beam scan }\end{array}$ \\
\hline
\end{tabular}
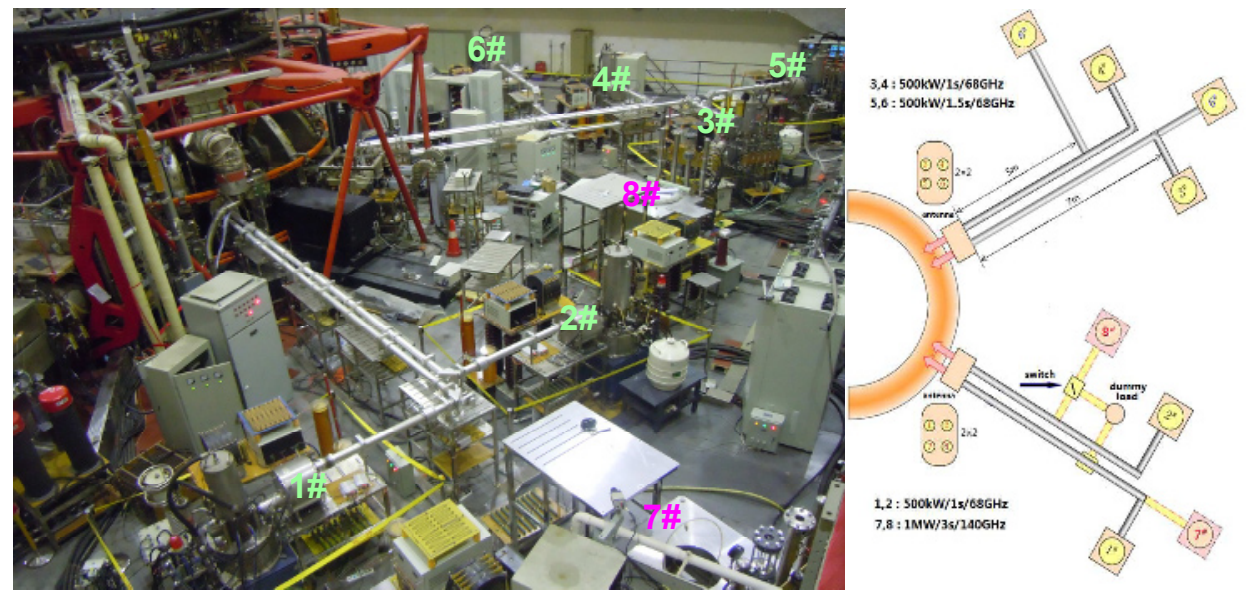

Fig. 1. Layout of overall ECRH system on HL-2A

So far, for the new $140 \mathrm{GHz}$ ECRH system on HL-2A, some problems should be considered and resolved compared with $68 \mathrm{GHz}$ system:

\section{Gyrotron and auxiliary system}

The two $1 \mathrm{MW} / 3 \mathrm{~s}$ gyrotrons are manufactured by GYCOM. The parameters of the gyrotron are shown in Table 2. CVD window must be used for long pulse duration and high output power.

Table 2 Parameters of $140 \mathrm{GHz}$ gyrotron

\begin{tabular}{|l|l|}
\hline & Parameter \\
\hline Frequency (GHz) & 140 \\
\hline Output power (MW) & 1 \\
\hline Pulse duration (s) & 3 \\
\hline Efficiency (\%) & 45 \\
\hline Window & CVD \\
\hline Polarization direction & Horizontal \\
\hline Type & CPD $^{(\%)}$ \\
\hline Output mode & TEM $_{00}$ \\
\hline Mode purity & $91 \%$ \\
\hline
\end{tabular}

\subsection{LHe free superconducting magnet}

A 5.8T liquid helium (LHe) free superconducting magnet system, which was designed for the $140 \mathrm{GHz}$ GYCOM gyrotron, was introduced from Cryomagnetics INC. The diagram of the magnet is shown in Figure 3. 

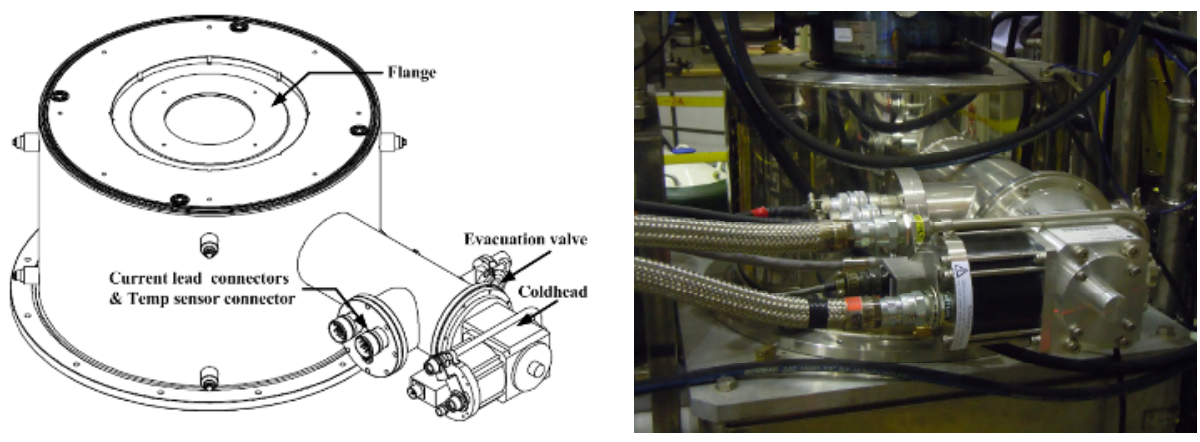

Fig. 2. Diagram and image of liquid helium free superconducting magnet

The magnetic filed distribution was measured after pre-adjusting the magnet and compared with the design value, shown in Figure 5(a). Basically, the magnet configuration can satisfy the operation requirements of $140 \mathrm{GHz}$ GYCOM gyroton. In order to examine the magnet configuration precisely, a dummy tube was used. After re-adjusting the magnet by measurement the axis and radial magnet field, the electron beam of dummy load was deposited at the collector uniformly and symmetrically, shown in Figure 5(b).

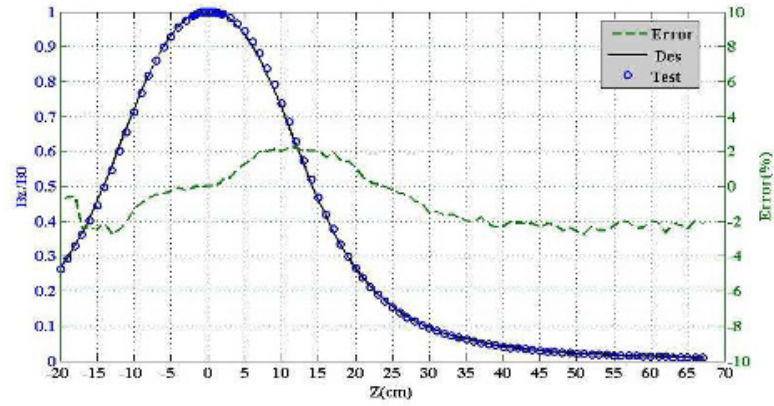

(a)

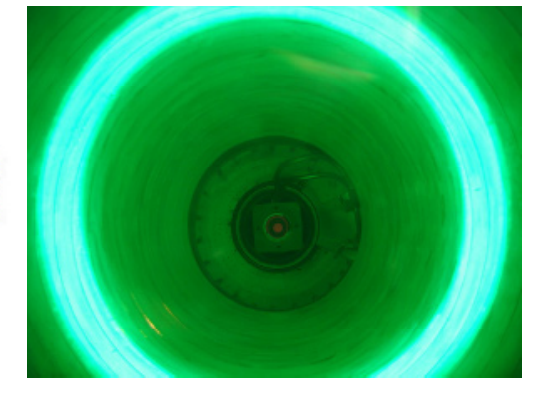

(b)

Fig. 3. (a) Measurement value and design value of magnetic filed distribution along the axis and the error between them. (b) Photograph of electron beam in dummy tube.

Based on the alignment of magnetic field, this LHe free superconducting magnet was tried to be applied on $68 \mathrm{GHz}$ GYCOM gyrotron, although originally it was designed for $140 \mathrm{GHz}$ gyrotron. With the gun coil, the output power $420 \mathrm{~kW} / 400 \mathrm{~ms}$ after MOU for $68 \mathrm{GHz} / 500 \mathrm{~kW} / 1 \mathrm{~s}$ gyrotron could be obtained by setting the magnetic field of this magnet as 2.62T. During last experimental campaign of HL-2A, this set of LHe free superconducting magnet system was operated on 5\# ECRH subsystem continually for about half a year and this sub-system could be operated at $350 \mathrm{~kW}$ stably. A conclusion could be gotten from the operation that this kind of LHe free superconducting could be widely used on different frequency gyrotron, if the parameter of gun coil was set properly.

\subsection{Power Supply and control system}

The parameters of power supplies for $140 \mathrm{GHz}$ gyrotron is shown in table 3. A PSM power supply with capability of $80 \mathrm{kV} / 100 \mathrm{~A}$ has been developed for the cathode of the two gyrotrons. All of the power supplies had been developed and tested with dummy load. The performance of all PS could satisfy the operation requirement of gyrotron.

Table 3 Parameters of power supplies for $140 \mathrm{GHz}$ gyrotron 


\begin{tabular}{|l|l|}
\hline \multicolumn{1}{|c|}{ PS } & \multicolumn{1}{|c|}{ Parameter } \\
\hline Cathode & PSM, $55 \mathrm{kV} / 45 \mathrm{~A}$, stability $1 \%$,turnoff time $<20 \mu \mathrm{s}$ \\
\hline Anode & $35 \mathrm{kV} / 180 \mathrm{~mA}$, stability $1 \%$,turnoff time $<10 \mu \mathrm{s}$ \\
\hline Filament & $40 \mathrm{~V} / 45 \mathrm{~A}$, stability $1 \%$ \\
\hline Ion pump & $30 \mathrm{kV} / 150 \mathrm{~mA}$ \\
\hline Magnet & Liquid helium free, $80 \mathrm{~A} / 10 \mathrm{~V}$, magnet field $5.8 \mathrm{~T}$ \\
\hline
\end{tabular}

The control and protection system use the distributed architecture based on industrial Ethernet to provide a good platform for the future expansion. The principle functions of control and protection system are:

- Integrate the $140 \mathrm{GHz}$ ECRH system into the $68 \mathrm{GHz}$ ECRH system

- Fast control for launcher, polarizer and high PS

- Slow control for cooling, vacuum and auxiliary PS of gyrotron

- Security and monitor system for all kinds of devices

- State monitor for status of security system, PS and operation situation

- Response time of arc and over-current protection $<10 \mu \mathrm{s}$

- Fiber isolation technology for security and stability of ECRH system

- Fast soft-protection technology based on CPLD/FPGA

\section{Transmission line}

The evacuated transmission line is based on $\Phi 63.5 \mathrm{~mm}$ corrugation waveguide. The length of transmission line is about $10 \mathrm{~m}$, and the transmitting efficiency is about $85 \%$. It is composed of the Optical Matching Unit (MOU), straight waveguide, bellow waveguide, polarizer, miter bend, DC break, switch, pumpout tee and dummy load. The layout of transmission line system is shown in Fig. 4.

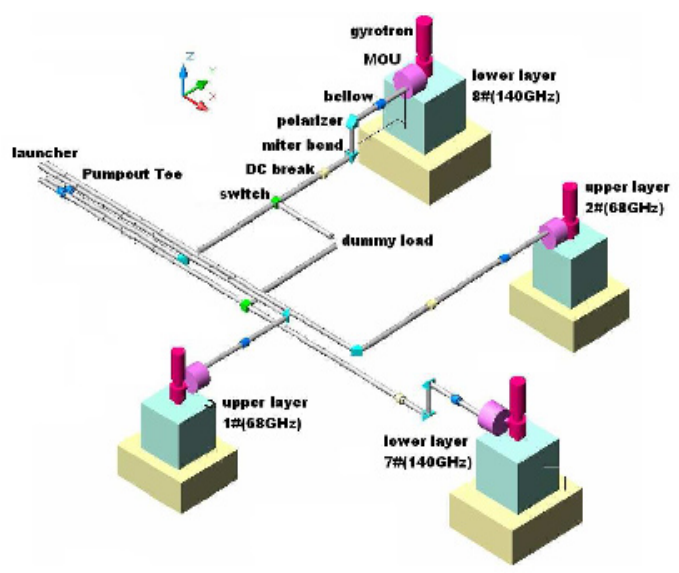

Fig. 4. Layout of transmission line

The vacuum degree of the transmission line, manufactured by GYCOM, is $10^{-2} \mathrm{~Pa}$. So the CVD window should be used on the launcher. $\lambda / 4$ and $\lambda / 8$ polarizers have been settled on the transmission line to obtain arbitrary polarization of wave beam. The design and manufacture of some components for high vacuum degree $\left(10^{-5} \mathrm{~Pa}\right)$ are ongoing, such as $1 \mathrm{~m}$ corrugated waveguide (Fig. 5(a)), DC break (Fig. 5(b)), polarizer rotated by servomotor (Fig. 5(c)), bellow and pumpout tee (Fig. 5(d)), and so on. 


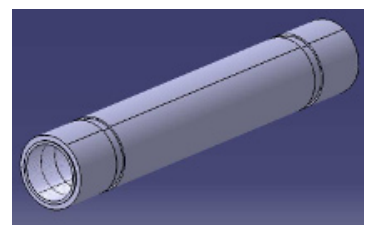

(a)

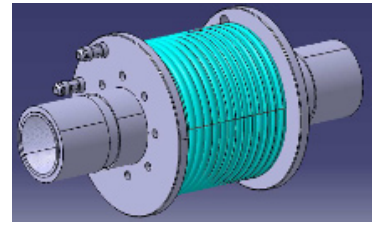

(b)

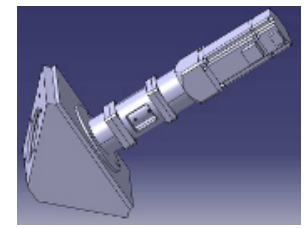

(c)

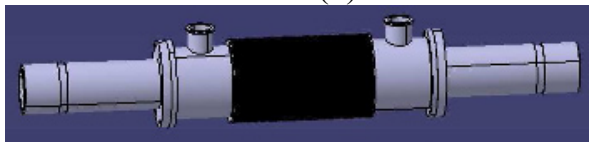

(c)

Fig. 5. Components of transmission line: (a) $1 \mathrm{~m}$ corrugated waveguide, (b)DC break, (c) polarizer driven by servomotor, (d) bellow and pumpout tee

\section{Launcher}

A new electron cyclotron resonance heating and current drive (ECRH/ECCD) launcher system has been designed and installed on the HL-2A tokamak to inject four beams and enable continuous millimeter-wave beam scanning in toroidal and poloidal directions independently for ECRH/ECCD experiments. The launcher is connected to four mm-wave lines capable of transmitting high power up to $3 \mathrm{MW}$ with two $1 \mathrm{MW} / 140 \mathrm{GHz} / 3 \mathrm{~s}$ and two $0.5 \mathrm{MW} / 68 \mathrm{GHz} / 1 \mathrm{~s}$ beams. The structure of the launcher is shown in Fig. 6.
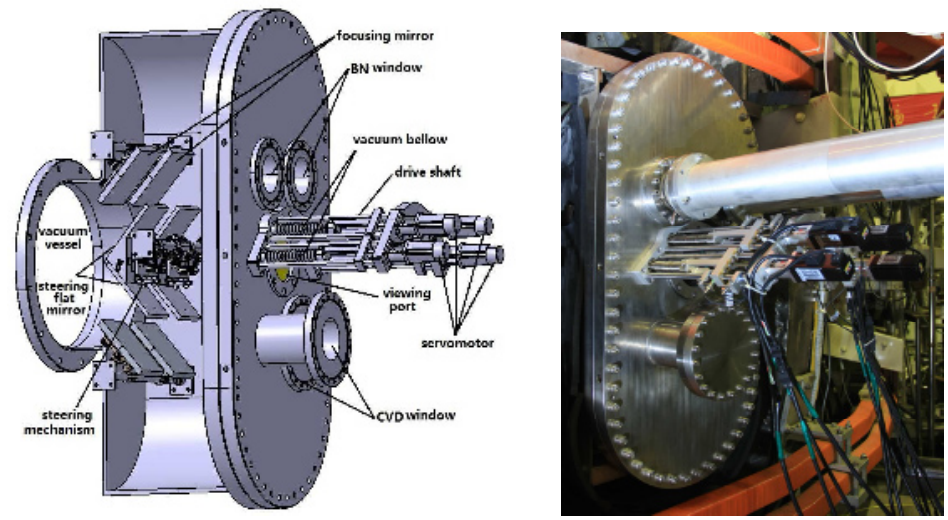

Fig. 6. Structure and image of launcher

The principle components and the main characteristics of the new launcher are:

- A container which normally operates under vacuum, houses the launching mirrors, the mounting and steering mechanism of the mirrors, two $\mathrm{BN}$ windows (for $68 \mathrm{GHz}$ ) and two CVD windows (for 140GHz).

- Four spherical focusing mirrors assure the maximum power density and sufficiently small spot size at the plasma centre for obtaining a narrow localized power deposition profile.

- Four steerable flat mirrors and steering mechanism are embedded in the launcher and far from the plasma edge under vacuum enabling extensive control of the injection angles for the beams.

- The flat mirrors are steered by a servomotor with drive shaft. All movements are linear displacements and transferred through bellows and drive shaft settled outside the vacuum vessel.

Based on ray tracing simulation by the TORAY-GA code, the scanning range of wave beams is $15^{\circ}-15^{\circ}$ in toroidal and $0^{\circ}-10^{\circ}$ in poloidal direction for $140 \mathrm{GHz}$ beams, which could cover half of the cross section of plasmas and can satisfy the requirements for advanced physical experiments. The beam radius in the plasma is $17.1 \mathrm{~mm}$ and $20 \mathrm{~mm}$ for the two $140 \mathrm{GHz}$ beams and $29.5 \mathrm{~mm}$ for the two 
$68 \mathrm{GHz}$ beams, respectively, allowing a very high localization of the absorbed power. The performance of the steering system was proven to be reliable and the linearity of the movement to be perfect. Additionally, the performance of injection of the wave beams was optimized by combination of setting the injection angle and polarization to realize desirable pure $\mathrm{O}$ or $\mathrm{X}$-mode injection.

\section{Conclusion}

The $140 \mathrm{GHz}$ ECRH system has been designed, which includes two $1 \mathrm{MW} / 3 \mathrm{~s}$ gyrotrons, two evacuated transmission line, a fast steerable launcher. The evacuated transmission line consists of MOU, $\Phi 63.5 \mathrm{~mm}$ corrugated waveguide run of $10 \mathrm{~m}$ in length, miter bends, polarizer, bellow, DC break, switch and pumpout tee. Design and manufacture of some components for high vacuum degree transmission line are on schedule. A new quasi-optical launcher has been designed and fabricated on HL-2A, which has the capability of two-dimensional beam scanning for obtaining narrow localized power deposition profiles and can inject two $140 \mathrm{GHz}$ and two $68 \mathrm{GHz}$ wave beams into the plasma together. Along with the beam injection direction control, the polarization and ellipticity of the beams can be controlled to launch the wave with the desired mode into the plasma. The excellence of the launcher in terms of relatively high freedom and reliability in control of the EC power deposition is attractive for exploring advanced physical experiments on HL-2A.

The launching mirrors could be rotated only shot by shot up to now. But new experiments on MHD instability control with ECRH/ECCD, especially for NTM instability, require a kind of realtime feedback launcher. ${ }^{[1][12]}$ The upgrading of the steering mechanism and control system is ongoing for this launcher. Moreover, the feedback signal which is calculated based on various plasma parameters provided by diagnostic systems is being considered and introduced into the control programs to change the ECW power deposition in real-time.

\section{ACKNOWLEDGMENTS}

The authors appreciate all the staff and researchers contributing to the ECRH system on HL-2A and the staff of GYCOM. We also would like to thank Prof. Shin KUBO of NIFS in Toki, Japan, and Dr. Roland Magne of CEA in Cadarache, France, for fruitful discussion and suggestion.

\section{References}

1. V. Erckmann, U. Gasparino, Plasma Phys. Control. Fusion 36, 1869 (1994)

2. B. Llyod, Plasma Phys. Control. Fusion 40, A119 (1998)

3. M. Thumm. 2003, Plasma Physics and Controlled Fusion, 45:A143

4. X.R. Duan et al., Nucl. Fusion 49, 104012 (2009)

5. X.R. Duan, et al., Nucl. Fusion 50, 095011 (2010)

6. R. Jun, et al., Nuclear Fusion and Plasma Physics, 29(4), 2009

7. M. Huang, et al., 3MW ECRH system and experiments on HL-2A, $37^{\text {th }}$ EPS conference, Dublin, Ireland (2010)

8. J. Zhou, et al., Development of 1MW ECRH transmission system in the HL-2A tokamak, Nuclear Fusion and Plasma Physics, Vol.27, No.4 (2007)

9. J. Zhou, et al., Design of the ECRH/ECCD Launcher System for HL-2A Tokamak, Plasma Science \& Technology, 8, 344-346 (2006)

10. C. Wang, et al., Design of the new antenna of ECRH system on HL-2A tokamak, Nuclear Fusion and Plasma Physics, Vol.30, No.4 (2010)

11. E. Westerhof, et al., A generic method for controlled ECRH/ECCD localization, EC13

12. J.W.Oosterbeek, et al., Design of a feedback system to stabilize instabilities by ECRH using a combined ECW launcher and ECE receiver, Fusion Engineering and Design 82(2007), 1117 1123 